REVIEW ARTICLE

\author{
H. Parmar \\ T. Rath \\ M. Castillo \\ D. Gandhi
}

\section{Imaging of Focal Amyloid Depositions in the Head, Neck, and Spine: Amyloidoma}

SUMMARY: Amyloidomas are benign tumorlike lesions consisting of localized deposits of amyloid and are the rarest form in the group of amyloidosis-related lesions. Diagnosis requires special stains; therefore, a high degree of suspicion for this disease is required. In this review, we describe the imaging features of amyloidomas involving the intracranial compartment, head and neck, and spine. We also discuss the differential diagnosis and briefly review the pertinent literature.

ABBREVIATIONS: FAP = familial amyloidotic polyneuropathy; $\mathrm{T} 1 \mathrm{WI}=\mathrm{T} 1$-weighted images; $\mathrm{T} 2 \mathrm{WI}=\mathrm{T} 2$-weighted images
A myloidosis is a disease complex resulting in the extracellular deposition of waxy insoluble fibrillar protein material called "amyloid.” It was first described by Rokitansky in 1842. ${ }^{1}$ Amyloid consists of relatively insoluble fibrils composed of polypeptide chains arranged in a twisted B-pleated sheet configuration. This particular protein configuration accounts for its characteristic staining properties and permits identification by light microscopy. It imparts unique chemical properties like resistance to protease digestion and insolubility, which promote continued deposition within organs. While amyloid can be suspected on routine hematoxylin-eosin sections, special stains are important for definitive diagnosis. With the polarized microscope, amyloid is seen to have a green birefringence when stained with Congo red.

Amyloid deposition can occur in a systemic or localized pattern, and deposits in both forms share similar physiochemical properties. Systemic amyloidosis includes primary amyloidosis related to plasma cell dyscrasias, reactive or secondary amyloidosis, and the familial forms. Localized amyloidosis includes organ-limited forms (skin, bladder, and endocrine system), focal amyloid deposits, and senile amyloidosis. Solitary or focal amyloidoma not associated with multiple myeloma is a rare entity with only a few cases or series reported in the literature. ${ }^{2-15}$ There is a marked preference for skull and spinal involvement. Other reported sites include the larynx, palate, orbits, sella, nasopharynx, lymph nodes, tracheobronchial tree, and abdominal wall. ${ }^{10,14,16-20}$ Patients with primary localized amyloidoma have no documented risk for the development of myeloma and no evidence of an increased mortality. In contrast, patients with systemic amyloidosis and myeloma have a markedly reduced life expectancy. ${ }^{3,4,11}$ The pathogenesis for the tumoral deposition of amyloid is unclear. Some authors argue that the amyloid fibril

From the Department of Radiology (H.P., T.R.), University of Michigan Health System, Ann Arbor, Michigan; Department of Radiology (M.C.), University of North Carolina, Chapel Hill, North Carolina; and Department of Radiology (D.G.), The Johns Hopkins Hospital, Baltimore, Maryland.

Previously presented as a scientific exhibit at: Annual Meeting of American Society of Neuroradiology, May 16-21, 2009; Vancouver, British Columbia, Canada.

Please address correspondence to Hemant Parmar, MD, Department of Radiology, University of Michigan, 1500 E Medical Center Dr, Ann Arbor, Ml 48109-0302; e-mail: parurad@ hotmail.com/ hparmar@umich.edu

Indicates open access to non-subscribers at www.ajnr.org

DOI 10.3174/ajnr.A1977 protein is either derived from components that leak from the vessels or is synthesized at the site of deposition. ${ }^{21}$

Several amyloid accumulations have been shown to have coexistent plasma cells. ${ }^{22-24}$ In an immunochemical and biochemical study, Vidal et $\mathrm{al}^{25}$ showed that the amyloidoma is related to a benign clonal proliferation of the plasma cells. Whether a solitary plasmacytoma can evolve from an amyloidoma remains to be determined. ${ }^{24}$ Laeng et $\mathrm{al}^{26}$ found immunoglobulin $\mathrm{H}$ gene rearrangement in 2 of 7 cases of nervous system amyloidomas, suggestive of an underlying B-cell neoplasia.

\section{Demonstrative Cases and Literature Review}

We evaluated 8 patients ( 3 men, 5 women; age range, 27-62 years) with amyloidoma involving the brain, head, neck, and the spine during 5 years. Clinical findings as well as laboratory test results were made available in all patients. CT scans $(n=$ $6)$ and MR images $(n=5)$ were obtained in all the patients. All patients had surgical procedures, in the form of either complete excision or biopsy; and all cases were shown to be amyloidoma on pathologic examination.

In a literature search, we found 30 cases of intracranial amyloidoma, ${ }^{6-8} 20$ cases involving the gasserian ganglion, ${ }^{9,16} 6$ cases of skull base amyloidoma, ${ }^{4,5}$ and 29 cases of amyloidoma involving the spine ( 8 cervical, 17 thoracic, 2 lumbar, and 2 sacral). ${ }^{2,3,12,13}$ The larynx was the most common site of involvement in the head and neck, followed by he orbits. ${ }^{11,18}$ Additional cases of amyloidoma reported in the head and neck region, often as single case reports, involved the pharyngeal wall, parotid gland, tonsil, lymph nodes and paranasal sinuses, brachial plexus, floor of the mouth, lip, tongue, and sublingual space, respectively. ${ }^{11,17-19}$

\section{Intracranial Amyloidoma}

Amyloid deposition within the brain can take many forms, including cerebral amyloid angiopathy, senile plaques of Alzheimer dementia, and deposits seen in the spongiform encephalitides of Kuru, Gerstmann-Straussler syndrome, and Creutzfeldt-Jacob disease. Tumorlike deposition (amyloidoma) is the least common form, with few previously reported cases. ${ }^{8}$ Notably, central nervous system amyloidomas are a different entity from systemic amyloidosis or from the more common congophilic amyloid angiopathy. ${ }^{27}$ They occur in isolation and have no known etiologic factors. The average patient age at presentation with cerebral amyloidoma is 47.8 

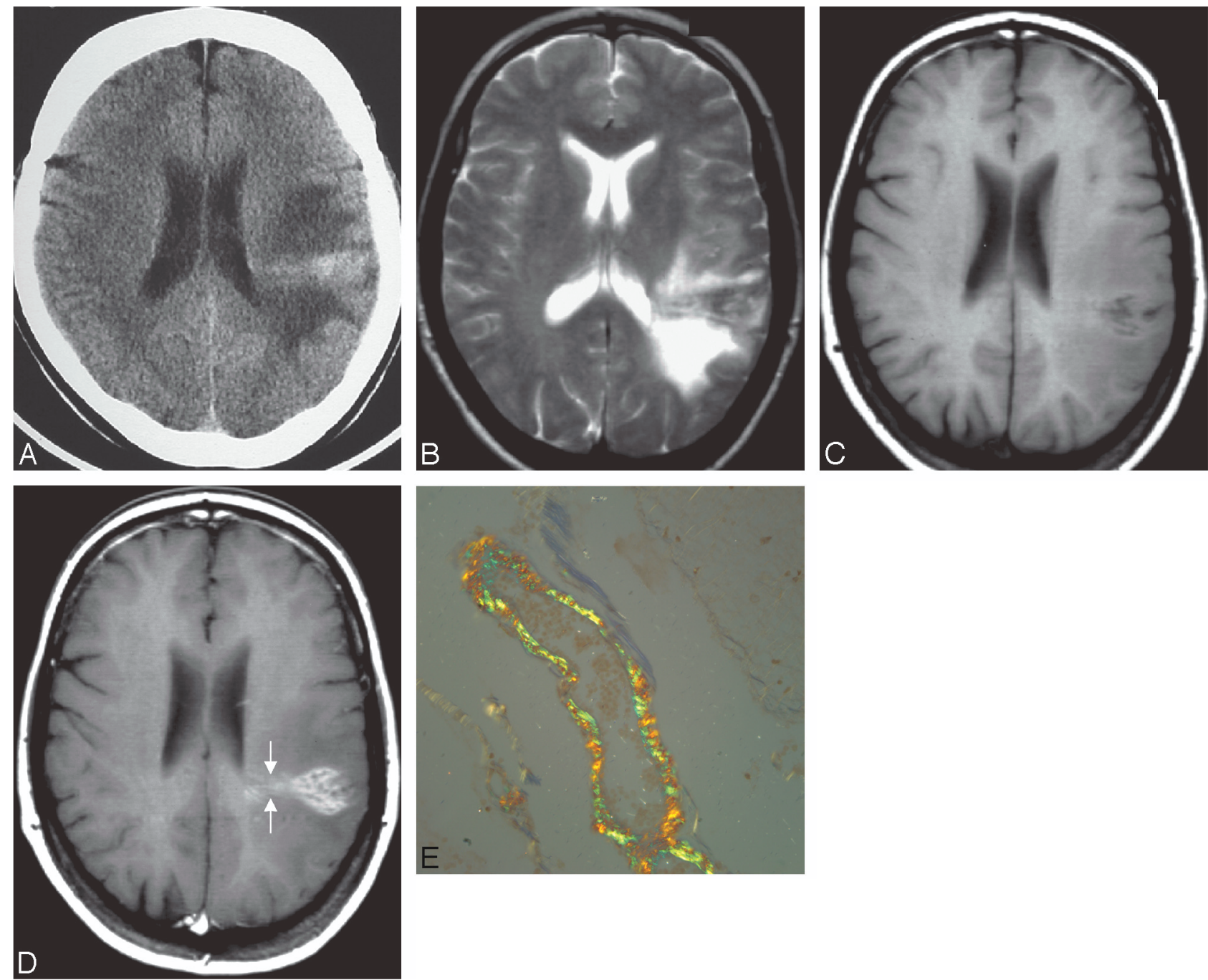

Fig 1. Intracranial amyloidoma in a 54-year-old woman with 2 episodes of left-hemispheric seizures. Axial $C T$ scan of the head without contrast $(A)$, axial T2-weighted image $(B)$, axial T1-weighted image precontrast $(C)$, axial postcontrast T1-weighted image $(D)$, and a histopathologic section stained with Congo red $(E)$. CT $(A)$ shows a hyperattenuated mass in the deep white matter with medial extension up to the lateral ventricular ependyma. On MR imaging $(B-D)$, the mass is iso- to hypointense on T1WI and T2WI and reveals marked enhancement on postgadolinium T1WI. D, Note the fine radiating lines at the medial aspect of the tumor (arrow), which are thought to be due to deposition of amyloid along the blood vessels, a finding frequently observed on histopathology. E, Courtesy of Mila Blaivas, University of Michigan, Ann Arbor, Michigan (Congo red, original magnification $\times 100)$.
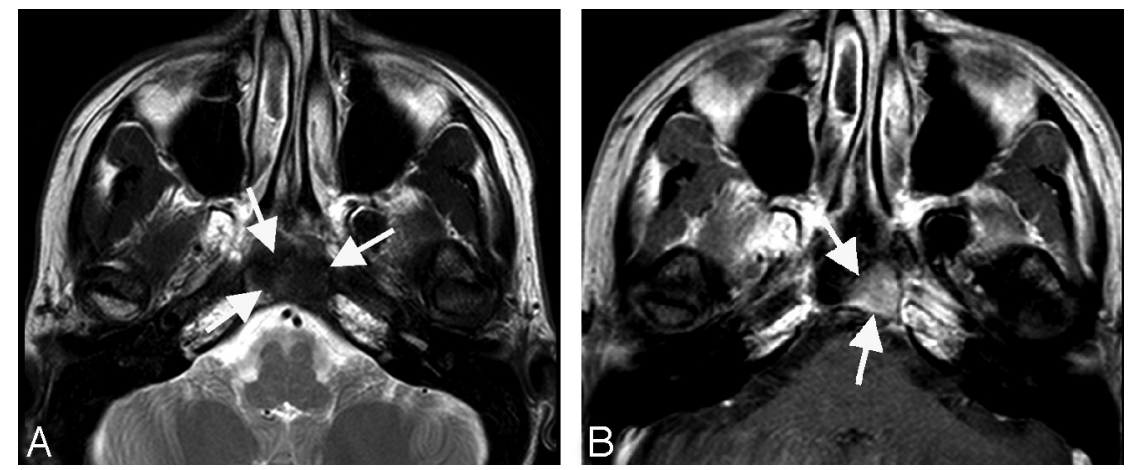

Fig 2. Clival amyloidoma in a 45-year-old woman with left facial numbness and pain for 1-2 months. MR imaging of the skull base shows a mass involving the left clivus. The mass (arrows) is hypointense on $\mathrm{T} 2 \mathrm{WI}(A)$ and shows homogeneous enhancement with contrast $(B)$.

years, and there is a slight female preponderance. Presenting features include seizures, headache, focal motor deficits, and cognitive decline. The mass usually is supratentorial, with only 1 reported case of simultaneous cerebral lobar and pontine involvement. ${ }^{27}$ On imaging, cerebral lobar white matter is most commonly affected, with occasional involvement of the cortex. Single and multiple lesions occur with similar frequency. These masses are iso- to hyperattenuated on unenhanced CT (Fig 1A). Hypointensity or mixed signal intensity on T2WI (Fig $1 B$ ) and iso- to slight hyperintensity on T1WI 

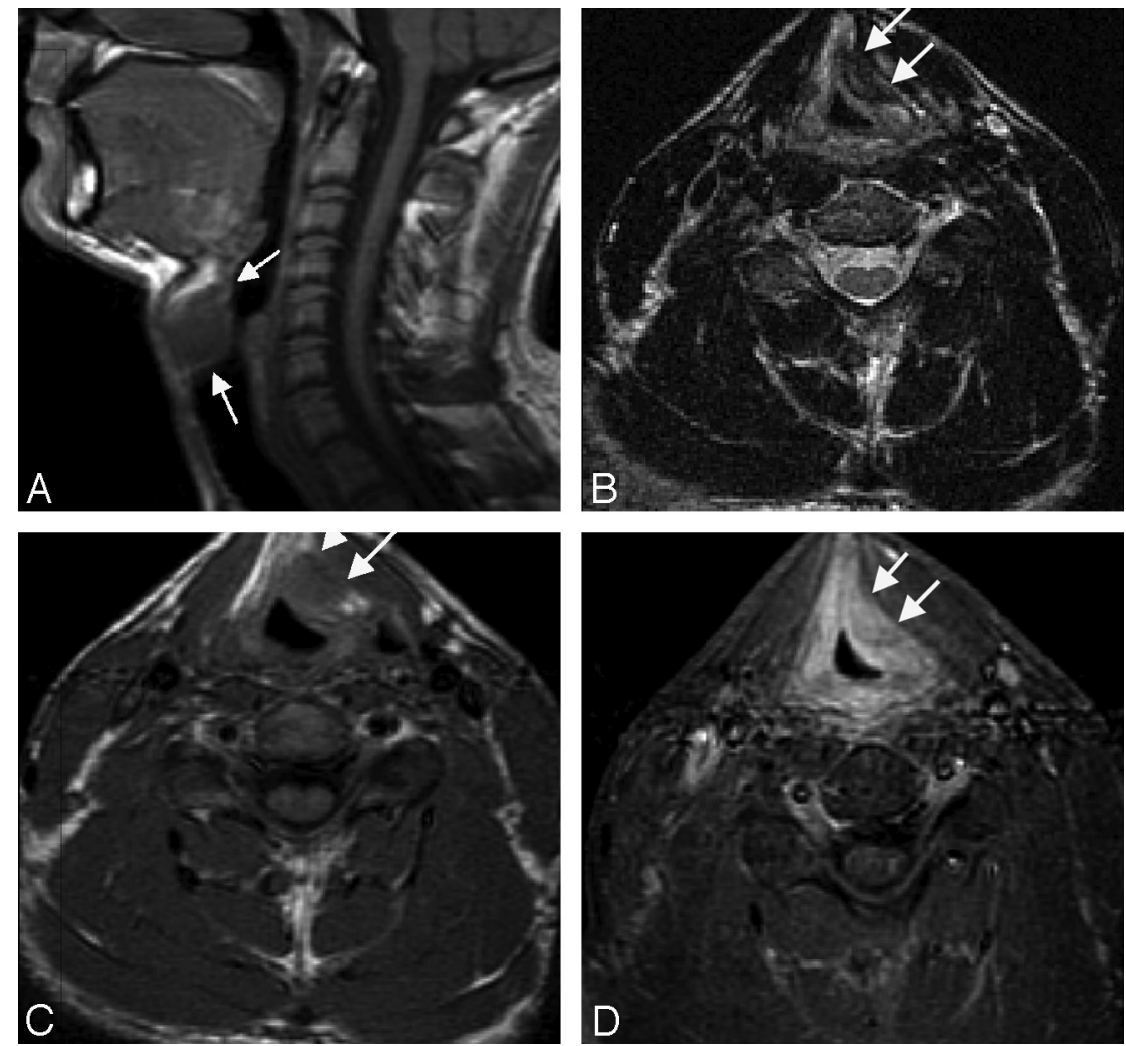

Fig 3. Laryngeal amyloidoma in a 27-year-old man with long-standing juvenile rheumatoid arthritis and progressive hoarseness. Sagittal T1-weighted image (A), axial T2-weighted image $(B)$, axial T1-weighted image $(C)$, and axial postcontrast with fat-saturation T1-weighted image $(D)$ demonstrate a 15-mm left supraglottic submucosal mass (arrows), which is isointense to muscle on $\mathrm{T} 1$ and enhances homogeneously with contrast. This lesion has notable decreased signal intensity on the T2Wl, suggestive of an orderly matrix with little free water. The lesion was pathologically proved to be amyloidoma. The patient did not have any evidence of systemic disease. Courtesy of Steve Gebarski, University of Michigan, Ann Arbor, Michigan.
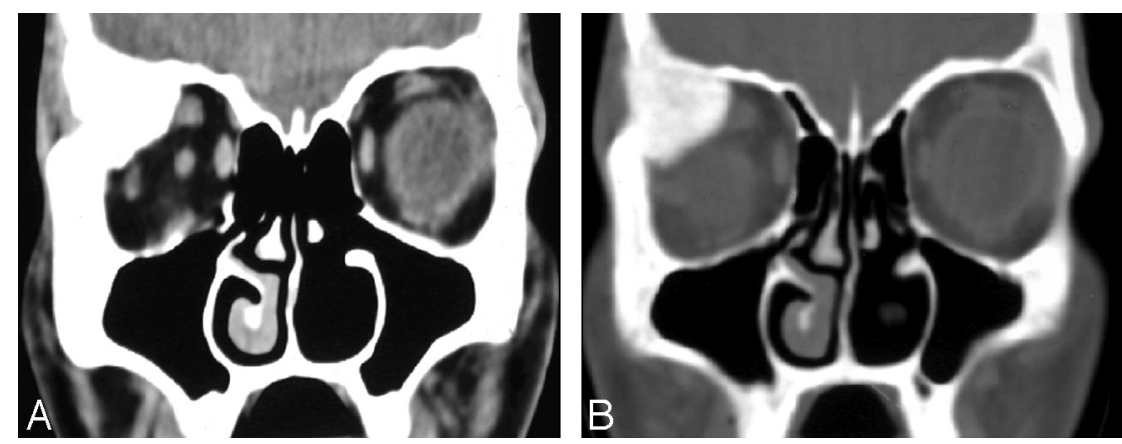

Fig 4. Orbital amyloidoma in a 32-year old woman with a slowly increasing mass in the right orbit and generalized bone pain. $A$, CT scan of the orbits shows a large mass involving the right superolateral orbit. $B$, The sclerotic/calcified mass involves the right frontal bone and the right lacrimal gland.

(Fig 1C) are observed due to nonuniform deposition of protein. The marked enhancement following contrast administration (Fig 1D) is secondary to the disruption of the bloodbrain barrier, attributed to the amyloid involvement in the blood vessel walls.

This same phenomenon is described in scintigraphic studies by using technetium Tc99m pertechnetate. ${ }^{8}$ Usually, there is lack of vasogenic edema and mass effect on surrounding structures. Cerebral angiographic results are normal, or they reveal vascular displacement by tumor. Most interesting, fine irregular radiating lines at the edge of the tumor have been described in some published cases (Fig 1D). ${ }^{8}$ These lines may indicate deposition of amyloid along the blood vessels, probably small-sized arteries, a finding that has been observed in pathology specimens (Fig 1E). ${ }^{28}$ Primary amyloidomas, though rare, should be included in the differential diagnosis of intra-axial masses that show little or no mass effect, are hyperattenuated on nonenhanced CT and hyperintense on T1WI, and show avid homogeneous enhancement with contrast.

\section{Amyloidoma of the Skull Base}

Although the brain parenchyma is the most common site for occurrence of intracranial amyloidomas, there are rare reports of amyloidomas involving the skull base, gasserian ganglion, cerebellopontine angle cistern, pituitary gland, and temporal bone. ${ }^{5,12,16}$ In amyloidomas involving the skull base, CT findings reveal a lytic, destructive, hypoattenuated somewhat expansive mass with nodular calcifications and marked en- 


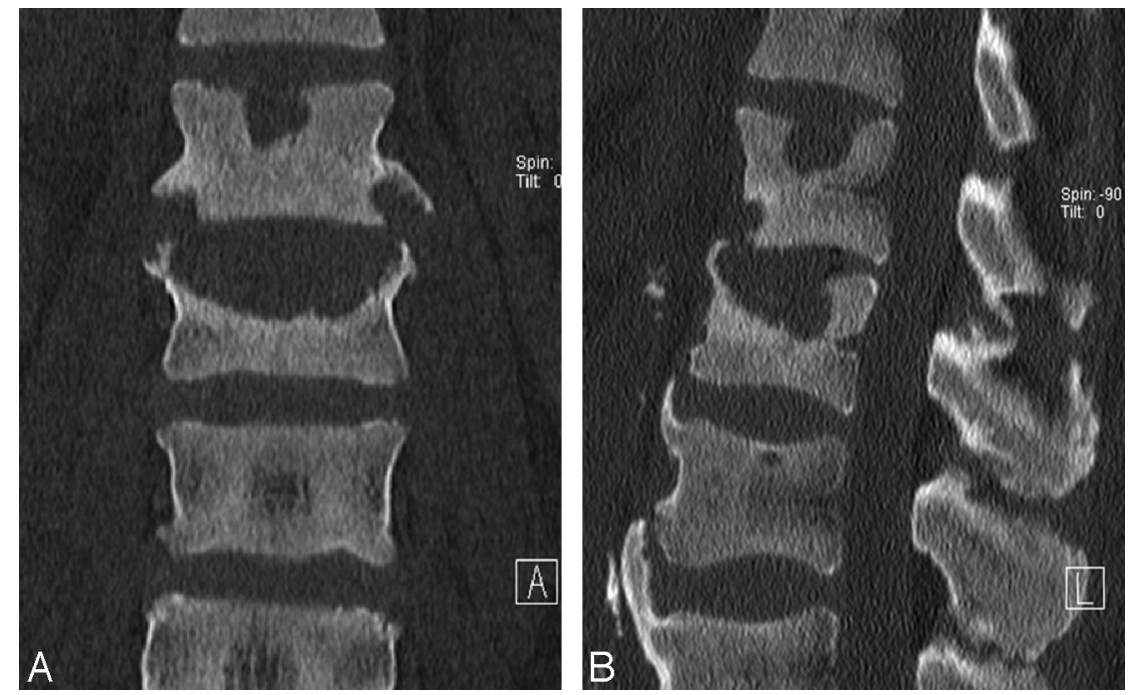

Fig 5. Thoracolumbar spine amyloidosis in a 54-year-old woman with back pain for a few-months' duration. Coronal and sagittal reformatted CT scan of the thoracolumbar junction reveals an irregular soft-tissue mass at the superior endplate, causing mild underlying sclerosis. The patient was initially treated for infection, but because there was no response, it prompted biopsy and amyloidosis was found.
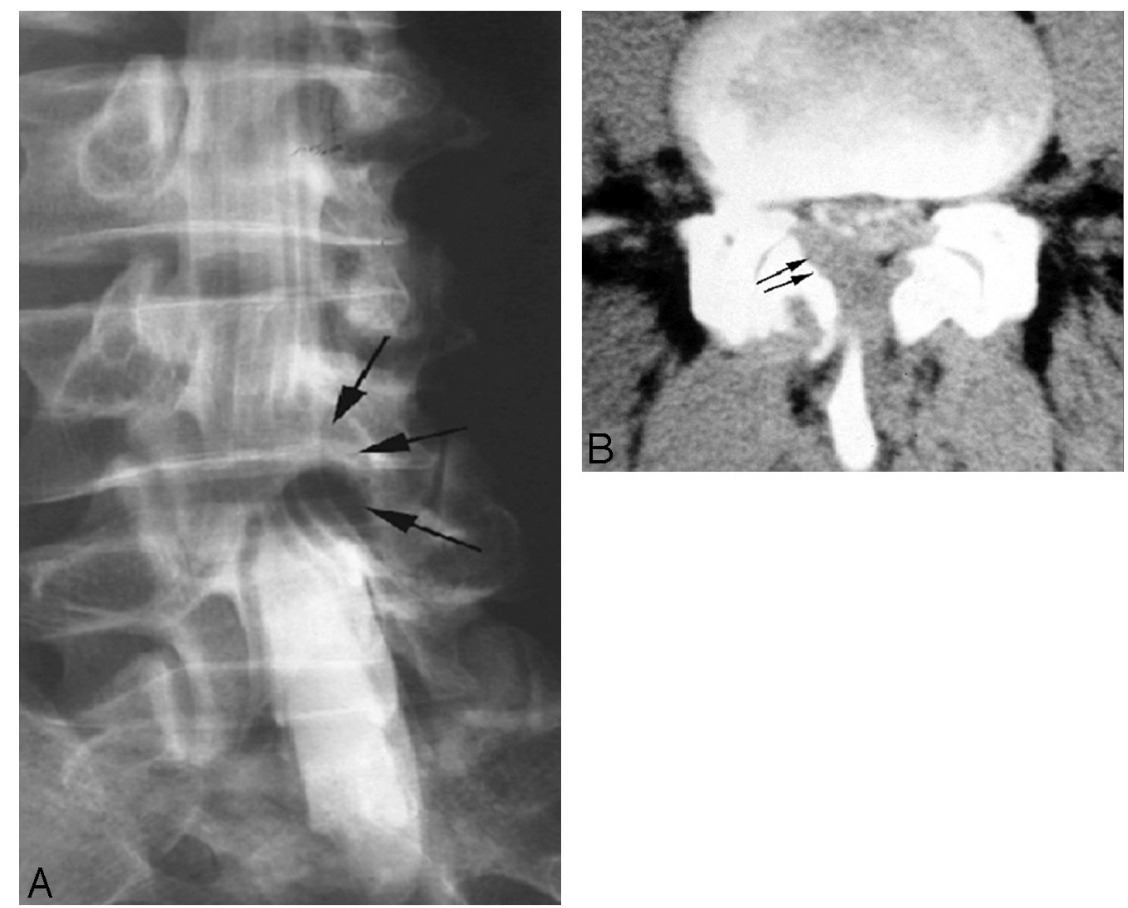

Fig 6. Thoracic spine amyloidoma in a 45-year-old woman with progressive back pain and lower limb paraparesis. $A$, Prone-oblique lumbar myelogram reveals an extradural mass at the level of the L4 vertebral body posterolateral to the thecal sac (arrows). B. CT myelogram at the same level shows a mass (arrows) in the ligamentum flavum, which was initially thought to be a synovial cyst. This turned out to be amyloidoma of ligamentum flavum. There was no evidence of systemic amyloidosis or plasma cell dyscrasia

hancement. ${ }^{5}$ On MR imaging, the T1 signal intensity is variable, but marked hypointensity is observed on T2WI (Fig $2 A$ ) followed by strong contrast enhancement (Fig $2 B$ ). This T2 shortening differentiates amyloidomas from chordomas and chondrosarcomas, which usually demonstrate high T2 signal intensity. ${ }^{5}$

\section{Amyloid Tumors of the Head and Neck}

Localized amyloid deposits have been described in a variety of sites in the head and neck, including the orbits, nasopharynx, lips, floor of mouth, tongue, larynx, and tracheobronchial tree. ${ }^{2-11,17-19}$ The imaging features are nonspecific. As opposed to amyloidomas of the larynx, the amyloid tumors at other head and neck sites generally have a more aggressive appearance.

\section{Laryngeal Amyloidoma}

Amyloidosis occurs twice as frequently in the larynx as in any other part of the head and neck and takes the form of tumorlike deposition or diffuse infiltration. Amyloidoma accounts for $0.2 \%-1.5 \%$ of benign laryngeal tumors. ${ }^{18}$ Peak occurrence is between the ages of 35 and 60 years with a 

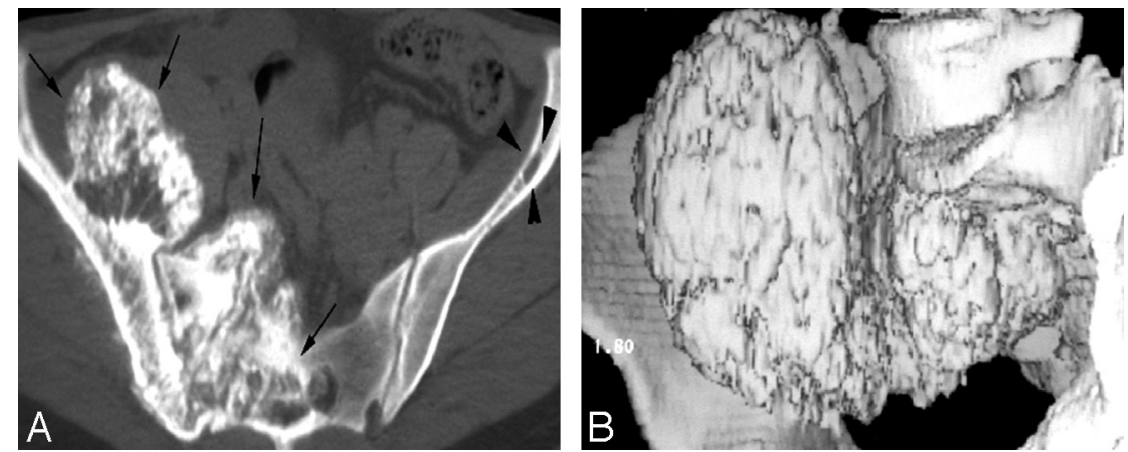

Fig 7. Pelvic bone involvement in a 62-year-old man with chronic low back pain radiating to the right lower extremity. Axial CT scan of the pelvis $(A)$ and shaded-surface display ( $B$ ) show a large destructive mass with exuberant calcifications involving the right ilium and sacrum (arrows) in a patient with multiple myeloma. Note the extension of the tumor into the sacral neural foramen on the right side. Multiple biopsies failed to demonstrate any plasma cells in this mass. Pathologic diagnosis was consistent with an amyloidoma.
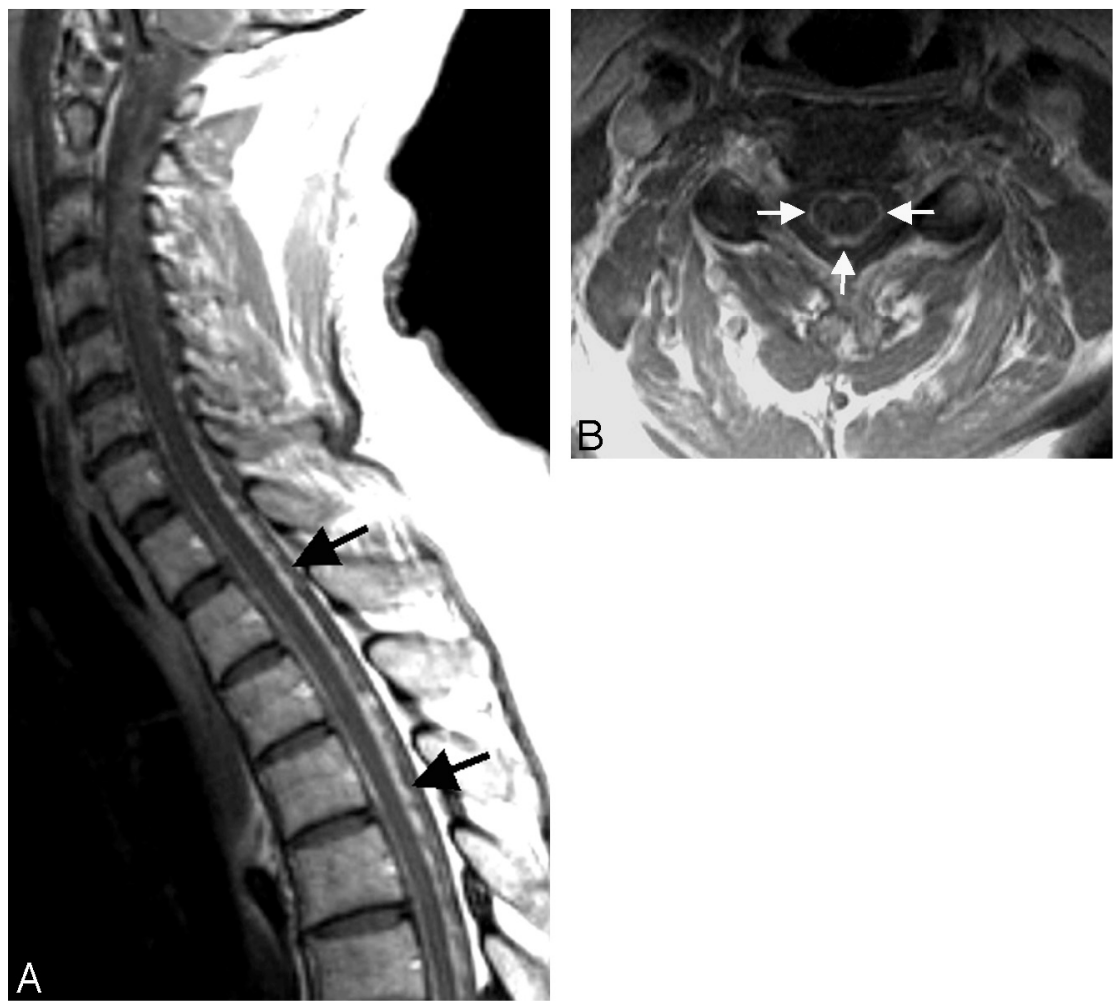

Fig 8. Spinal MR imaging in a 44-year-old woman with progressive numbness and weakness of all 4 extremities and mild autonomic dysfunction. Sagittal and axial postcontrast-enhanced T1-weighted image shows extensive pial enhancement, completely coating the surface of the cervical and thoracic cord (arrows). Amyloid deposits were found at biopsy.

male-to-female ratio of 3:1. Patients usually present with hoarseness, difficulty breathing, neck pain, and, uncommonly, hemoptysis. The supraglottic larynx, especially the false vocal cord, is the most commonly involved region. ${ }^{18}$ On CT, laryngeal amyloidoma appears as a well-defined submucosal homogeneous mass with occasional punctate calcifications. Unlike amyloidomas in the skull base or spine, there is no bony erosion. On MR imaging (Fig 3), the lesion reveals intensity equal to that of surrounding muscles on T1WI and remains isointense or slightly hyperintense on T2WI. In comparison, chondrosarcoma of the larynx is hypo- to isointense on T1WI and hyperintense on T2WI, which parallels the appearance of mature hyaline cartilage. Therefore, T2 signal-intensity characteristics might help differentiate amyloidoma from chondrosarcoma. ${ }^{19}$

\section{Orbital Involvement}

Orbital amyloidomas are very rare but may have a characteristic clinical and radiologic appearance. Most patients reported in the literature had a firm mass in the upper orbit with a predilection for the region of the lacrimal gland. ${ }^{20} \mathrm{CT}$ shows a homogeneous mass with thickening and irregularity of the adjacent bone and/or calcification within the mass (Fig 4). Amyloidosis of the conjunctiva and orbits is almost always a benign disease without systemic implications, whereas amyloid involving the skin of the eyelids is a hallmark of generalized amyloidosis. ${ }^{20}$

\section{Spinal Involvement}

Primary solitary amyloidoma of the spine is very rare, with fewer than 30 cases reported. ${ }^{2,3,12,13}$ It has an unusually aggressive appearance characterized by local deposition of amyloid 
with bony destruction and soft-tissue extension. There is no detectable plasma cell dyscrasia or abnormal serum protein. The thoracic spine is most commonly involved, followed by the cervical spine. Bony destruction caused by spinal amyloidoma mimics other aggressive pathologic processes, including infection, neoplasm, or malignancy and metabolic diseases such as gout (Fig $5 A,-B) .{ }^{29}$ The primary form of spinal amyloidosis is uncommon compared with amyloid-related spinal spondyloarthropathy seen in patients with chronic renal failure and long-term dialysis. Carpal tunnel syndrome is often associated in such patients. ${ }^{30}$

Sometimes, localized deposits of amyloid appear as densely calcified lesions on CT and plain films (Figs 6A, $-B$ and $7 A,-B$ ). They commonly extend into the soft tissues. Findings mimic chondrosarcoma, osteogenic sarcoma, or calcified metastatic tumor. Amyloid deposits show intense uptake of bone radiotracer because of the associated ectopic ossification and calcification. The MR imaging signal-intensity characteristics are similar to those of primary amyloid lesions elsewhere in the bones and soft tissues and include low-to-intermediate signal intensity on T1WI, intermediate-to-low signal intensity on T2WI, and variable enhancement on contrast-enhanced T1WI.

\section{Meningeal Deposits}

Amyloidosis involvement of the leptomeninges, without cerebral parenchymal vascular involvement, is exceptionally rare. $^{31,32}$ This is often a familial disorder associated with vitreous amyloid deposits and seen in oculoleptomeningeal amyloidosis or FAP. Pathologically, vascular, leptomeningeal, subpial, subependymal, and choroid plexus deposition of amyloid with sparing of intracerebral blood vessels is seen. Sometimes in FAP, there are massive deposits of amyloid. Clinically, the patients can present with myelopathy symptoms or radiculopathy. ${ }^{30}$ Imaging features are nonspecific; other entities producing diffuse leptomeningeal enhancement like infection, neoplasm (primary or secondary), and inflammatory entities like sarcoidosis need to be excluded. When diffuse leptomeningeal enhancement (Fig $8 A,-B$ ) is associated with hypertrophy of the ligaments within the spinal canal and thickening of the nerve roots, one should consider amyloidosis related to FAP in the differential diagnosis. ${ }^{31}$

\section{Conclusions}

Amyloidomas are slow-growing benign lesions that generally have a favorable prognosis as opposed to systemic amyloidosis. Complete evaluation should be performed in every patient to exclude associated systemic amyloidosis and plasma cell dyscrasia. Imaging features are variable and can mimic slow-growing neoplasms in the brain and head and neck. Intracranial amyloidoma should be considered in solitary or multiple masses with little or no mass effect, hyperattenuation on CT scans, and variable T1 and T2 signal intensity with homogeneous enhancement with contrast. Amyloidomas in the orbits and larynx are well-defined masses with benign imaging features, but lesions elsewhere in the head and neck and spine and at the skull base often show aggressive features and can mimic aggressive diseases like infection or malignant neoplasm.

\section{References}

1. Rokitansky K. Handbuch der Pathologischen Anatomie. Vienna, Austria: Braunmuller and Seidel; 1842;311:384-424

2. Mizuno J, Nakagawa H, Tsuji Y, et al. Primary amyloidoma of the thoracic spine presenting with acute paraplegia. Surg Neurol 2001;55:378-82

3. Iplikcioglu AC, Bek S, Gokduman CA, et al. Primary solitary cervical amyloidosis: case report and review of the literature. Spine 2007;32:E45-47

4. Shenoy SN, Raja A. Amyloidoma of the craniovertebral junction. Neurol India 2004;52:241-42

5. Simoens WA, van den Hauwe L, Van Hedent E, et al. Amyloidoma of the skull base. AJNR Am J Neuroradiol 2000;21:1559-62

6. Ragel AT, Blumenthal DT, Browd SR, et al. Intracerebral amyloidoma can mimic high-grade glioma on magnetic resonance imaging and spectroscopy. Arch Neurol 2006;63:906-07

7. Tabatabai G, Baehring J, Hochberg FH. Primary amyloidoma of the brain parenchyma. Arch Neurol 2005;62:477-80

8. Gandhi D, Wee R, Goyal M. CT and MR imaging of intracerebral amyloidoma: case report and review of the literature. AJNR Am J Neuroradiol 2003;24:519-22

9. Yu E, de Tilly LN. Amyloidoma of Meckel's cave: a rare cause of trigeminal neuralgia. AJR Am J Roentgenol 2004;182:1605-06

10. Penner CR, Muller S. Head and neck amyloidosis: a clinicopathologic study of 15 cases. Oral Oncol 2006;42:421-29

11. Georgiades CS, Neyman EG, Fishman EK. Cross-sectional imaging of amyloidosis: an organ system-based approach. J Comput Assist Tomogr 2002; 26:1035-41

12. Unal A, Sutlap PN, Kýyýk M. Primary solitary amyloidoma of thoracic spine: a case report and review of the literature. Clin Neurol Neurosurg 2003;105:167-69

13. Dickman CA, Sonntag VK, Johnson P, et al. Amyloidoma of the cervical spine: a case report. Neurosurgery 1988;22:419-22

14. Fougeres A, Gagnon J, Boisvert P. Calcified amyloidoma of larynx. Can Assoc Radiol J 1999;50:418-20

15. Kerner UM, Wang MB, Angier G, et al. Amyloidosis of the head and neck. a clinicopathlogic study of the UCLA experience, 1955-1991. Arch Otolaryngol Head Neck Surg 1995;121:778-82

16. Vorster SJ, Lee JH, Ruggieri P. Amyloidoma of the gasserian ganglion. AJNR Am J Neuroradiol 1998;19:1853-55

17. Pang KP, Chee LW, Busmanis I. Amyloidoma of the nose in a pediatric patient: a case report. Am J Otolaryngol 2001;22:138-41

18. Godbersen GS, Leh JF, Hansmann ML, et al. Organ-limited laryngeal amyloid deposits: clinical, morphological, and immunohistochemical results of five cases. Ann Otol Rhinol Laryngol 1992;101:770-75

19. Hegarty JL, Rao VM. Amyloidoma of the nasopharynx: CT and MR findings. AJNR Am J Neuroradiol 1993;14:215-18

20. Knowles DM 2nd, Jakobiec FA, Rosen M, et al. Amyloidosis of the orbit and adnexae. Surv Ophthalmol 1975;19:367-84

21. Eriksson L, Sletten K, Benson L, et al. Tumor-like localized amyloid of the brain is derived from immunoglobulin light chain. Scand J Immunol 1993;37:623-26

22. Harris JH, Rayport M. Primary cerebral amyloidoma. J Neuropathol Exp Neurol 1979;38:318

23. Spaar FW, Goebel HH, Volles E, et al. Tumor-like amyloid formation (amyloidoma) in the brain. J Neurol 1981;224:171-82

24. Cohen M, Lanska D, Roessmann U, et al. Amyloidoma of the CNS. I. Clinical and pathologic study. Neurology 1992;42:2019-23

25. Vidal RG, Ghiso J, Gallo G, et al. Amyloidoma of the CNS. II. Immunohistochemical and biochemical study. Neurology 1992;42:2024-28

26. Laeng RH, Altermatt HJ, Scheithauer BW, et al. Amyloidomas of the nervous system: a monoclonal B cell disorder with monotypic amyloid light chain amyloid production. Cancer 1998;82:362-74

27. Symko SC, Hattab EM, Steinberg GK, et al. Imaging of cerebral and brain stem amyloidomas. AJNR Am J Neuroradiol 2001;22:1353-56

28. Weller RO, Massey A, Newman TA, et al. Cerebral amyloid angiopathy: amyloid $\boldsymbol{\beta}$ accumulates in putative interstitial fluid drainage pathways in Alzheimer's disease. Am J Pathol 1998;153:725-33

29. Hwang SS, Park YH, Kim JY, et al. Primary amyloidoma of the cervical spine. AJNR Am J Neuroradiol 2000;21:601-03

30. Davidson GS, Montanera WJ, Fleming JF, et al. Amyloid destructive spondyloarthropathy causing cord compression: related to chronic renal failure and dialysis. Neurosurgery 1993;33:519-22

31. Herrick MK, DeBruyne K, Horoupian DS, et al. Massive leptomeningeal amyloidosis associated with Val30Met transthyretin gene. Neurology 1996;47: 988-92

32. Kitajima M, Korogi Y, Yamura M, et al et al. Familial amyloid polyneuropathy: hypertrophy of ligaments supporting the spinal cord. AJNR Am J Neuroradiol 2004;25:1599-602 